\title{
The Impact of Sleep Deprivation on Work Performance towards Night-shift Healthcare Workers: An Evidence-based Case Report
}

\author{
Muhammad Habiburrahman, BMedSci, MD, ${ }^{1}$ Elvira Lesmana, BMedSci, MD, ${ }^{1}$ \\ Fadhilah Harmen, BMedSci, MD, ${ }^{1}$ Nadya Gratia, BMedSci, MD ${ }^{1}$ and Listya Tresnanti Mirtha, MD, PhD ${ }^{2,3}$ \\ ${ }^{1}$ Faculty of Medicine, Universitas Indonesia, Jakarta, Indonesia \\ ${ }^{2}$ Department of Community Medicine, Faculty of Medicine, Universitas Indonesia, Jakarta, Indonesia \\ ${ }^{3}$ Hospital of Universitas Indonesia, Depok, Indonesia
}

\begin{abstract}
Background. Poor sleep and excessive fatigue among workers can reduce well-being and physical fitness. However, not many studies have mentioned how sleeping deprivation among night-shift healthcare workers impacted their work performance in multiple aspects.

Method. We conducted an evidence-based case report (EBCR) of a night shift nurse who was worried about the impact of her sleep deprivation on her work performance in the future due to prior history of needle-stick injuries. We aimed to determine whether sleeping deprivation caused by regular night shifts leads to decreased work performance among night-shift healthcare workers by formulating a clinical question. Evidence was searched systematically using five major journal databases (Proquest, EBSCO-Host, PubMed, ScienceDirect, and Cochrane) and was assessed thoroughly using inclusion and exclusion criteria.

Results. Eleven eligible studies were obtained with a medium level of evidence (III-IV), three systematic reviews with meta-analyses (SR-MA), three SR without MA, and five observational studies. All of them were analyzed and critically appraised using Oxford Evidence-Based Medicine and Joanna Briggs Institute tools. We found that reduced quantity and quality of sleep impacted all dimensions of work performance among healthcare professionals, be it in task performance (e.g., skill proficiency), contextual performance (e.g., communication skill and mental health issues), and patient and health worker safety (accident and medication error). It could also encourage counterproductive work behavior, such as absenteeism. Furthermore, sleep deprivation changes circadian rhythms, causing decreased information processing and affective recognition functions in some vital brain areas, ultimately affecting several work dimensions.
\end{abstract}

Conclusion. In conclusion, stakeholders need to adjust proper shift scheduling for health care workers, practice sleep hygiene, maintain physical fitness, and consume nutritional food, positively correlated to health and productivity.

Key Words: evidence-based medicine, healthcare worker, night shift, sleep deprivation, work performance

Paper presented in the $2^{\text {nd }}$ International Conference on Mining Occupational Safety and Health - International Commission on Occupational Health (MinOSH-ICOH) and in the $13^{\text {th }}$ Indonesian Occupational Medicine Update (IOMU) on October 6-8, 2019, at Bali, Indonesia.

Corresponding author: Listya Tresnanti Mirtha, MD, PhD Department of Community Medicine

Faculty of Medicine

Universitas Indonesia

Jl. Pegangsaan Timur No. 16, Central Jakarta, Indonesia

Email: tresnanti.listya@ui.ac.id

\section{INTRODUCTION}

In 2019, estimations suggested that 3.3 billion workers from the 7.75 billion world population are employed globally. ${ }^{1}$ In the Asia-Pacific region, 1.9 billion persons are employed, accounting for $57.6 \%$ of the workforce in the world. $^{2}$ The number of health workers was around 43.5 million in 2013 and will increase by 55\% in 2030; one possible reason is the high workload during the COVID-19 pandemic. ${ }^{3}$ In the Asia region, there were approximately 6.2 million healthcare professionals in 2013, and the number 
will increase by $75 \%$ in 2030 , ranking $4^{\text {th }}$ after the European, Western Pacific, and Americas regions. ${ }^{3}$

Following United Nations' 17 Sustainable Development Goals (SDGs) goals, good health and work concerns are fundamental issues. The objective of the SDGs is inseparable from the inevitable large number of health professions. ${ }^{4}$ Health occupations are in the high-risk category of high workloads and rough working time, bringing us to health and work performance concerns. Several studies highlighted poor sleep and excessive fatigue among shift workers can reduce well-being and physical fitness. However, it still became a question whether sleep deprivation among night shift health workers had a broad impact on work performance..$^{5-8}$ Safety also becomes the most significant concern in patient care and occupational health for health professionals. The International Labour Organization (ILO) estimated that about 2.3 million workers worldwide suffer work-related accidents or diseases every year. ${ }^{9}$ Particularly in the health workers population, the incident rates for non-fatal injuries related to work in 2017 were $100-150$ per $10,000 .{ }^{10}$ Work-related injuries impact the health sector and impose an economic burden due to spending up to $4-6 \%$ of the Gross Domestic Product (GDP) in various countries across the world. ${ }^{8}$

All sleeping problems and their impact on night shift health professionals have raised issues in occupational health because it was suspected to affect work performance in health services and patient care. ${ }^{11,12}$ However, currently, to our knowledge, there are no studies that present and discuss comprehensively valid evidence about the impact of sleep deprivation on healthcare workers; indeed, this is often questioned by healthcare professionals who naturally have to frequently deal with the quality and quantity of sleep due to night shifts leading to sleep deprivation. In addition, not many general physicians acknowledge the impact of sleep deprivation on the night shift and can satisfactorily answer patients' questions. This issue incited us to conduct an evidence-based case study from a question raised by our patient who worked as a nurse and who suffered a needle stick injury during a night shift in a hospital. She was worried about whether her previous work accident was related to sleep deprivation. If so, what other work performance will be affected as a health worker if she frequently experiences sleep deprivation.

Therefore, we aimed to present a case report and investigated the evidence about the impact of sleep deprivation on night shift healthcare workers' performance, including the physiological-neurocognitive behavioral mechanism pathway that underlies work performance changes to yield comprehensive recommendations for a better health sector.

\section{Case Illustration}

Mrs. A (35 years old) is a nurse in a private hospital. She came to a general practitioner due to dizziness, lack of concentration, heartburn, and lethargy in the past three months. These complaints caused her to make frequent mistakes in the hospital. For example, two days before the consult, she accidentally stuck a syringe in her finger while injecting drugs to her patient. Routinely, she worked for 8 hours a day and was on night shifts three times a week. If a friend could not fulfil a night shift, she would replace her friend's night shift. She frequently felts sleepy at work, had difficulty falling asleep at night, woke up in the middle of the night, felt tired, and was not well-rested upon waking up in the morning, although she had spent 8 hours sleeping (while not in the morning night shift duty). There was no marital conflict in her marriage, and her husband fully supported her career. She had no symptoms of depression, nor was she on sleeping pills.

General physical examination revealed that the patient was conscious and comfortable, and vital signs were stable, with only slight tachycardia (110 bpm). There were no significant abnormalities in the head-to-toe assessment. An inactive bloodless stab wound and bruise on the left middle finger were treated according to the standard operating procedure as a needle stick injury case at her hospital emergency room.

The patient is obese according to both the WHO and Asia-Pacific guidelines for Body Mass Index (BMI) classification $\left(27.23 \mathrm{~kg} / \mathrm{m}^{2}\right)$. A laboratory test at the pricking incident and two days before consult showed negative results for HIV, Hepatitis B, and Hepatitis C. Complete blood count examination was within normal limits.

The patient was worried about her sleeping problem and was curious whether the situation would affect her performance in the hospital.

\section{Clinical Question}

In this case report, the writers explored the clinical question; "does night shift healthcare workers' sleep deprivation affect their working performance?". This question was translated to a PEO (patients, exposures, and outcomes) formula to collect evidence systematically:

P: night-shift healthcare workers

E: sleeping deprivation

O: working performance

\section{METHODS}

\section{Materials and Method}

Patient data were obtained from medical records, history taking, and physical examination with the patient's consent supported by previous laboratory results at the hospital where she worked. We used the evidence-based case report (EBCR) design to interpret problems in the case and looked for the best management by approaching the evidence systematically. We focused on the clinical question about sleeping deprivation on working performance among night-shift healthcare workers as the main problem. We systematically managed high-quality evidence by critically reviewing the literature for its validity, importance, and applicability. Furthermore, 
we summarized the findings to address the patient's problem and gave evidence-based recommendations. ${ }^{13-16}$

A literature search was conducted on September 1, 2019, with the combination of keywords and their synonyms: "worker," "sleep deprivation," "work performance," and "night shift" using Booleans AND, OR, NOT, as well as asterisk, parentheses, and quotation marks to enhance specificity and sensitivity (exact keywords are shown in Figure 1).

Five journal databases were used: Proquest, EBSCOHost, PubMed, ScienceDirect, and Cochrane. A second

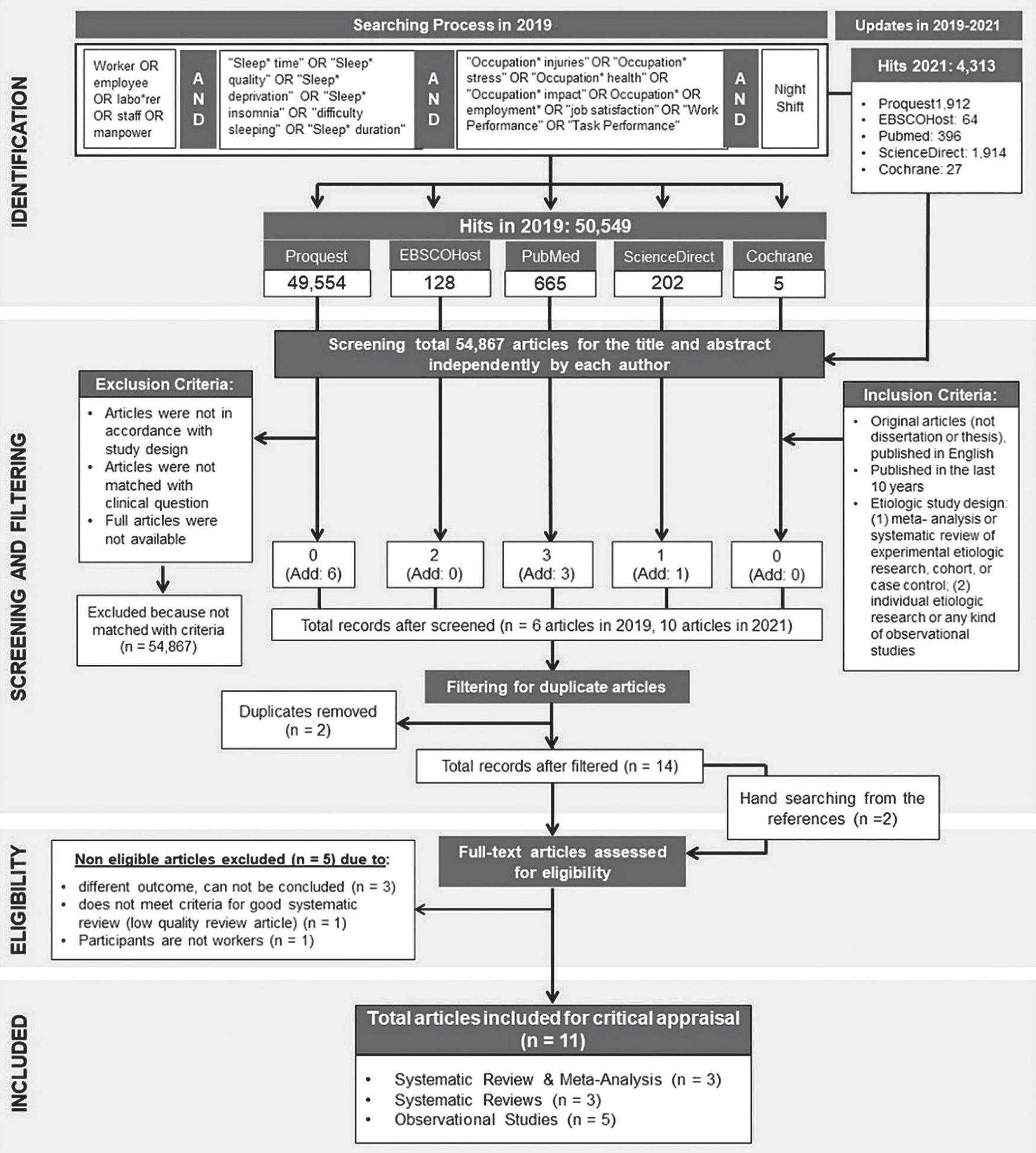

Figure 1. Flowchart of the selection process. 
search to enhance and update the search results was made on March 18, 2021, for newly published articles between 2019 and 2021. The keyword "night-shift healthcare workers" was omitted because it was too specific and limited literature hits. Instead, the word "worker" and its synonyms were used. The resultant records were sorted to select only healthcare workers as the study population.

All references were screened for the title and abstract and were filtered with the following inclusion criteria: (1) studies involving human subjects, (2) published in English, (3) compatible with the clinical question and the etiological study design, and (4) published in the last ten years. In addition, we excluded studies that did not follow the study design or the clinical question and if the full text was not available.

Sixteen articles were collected, six from the 2019 search and ten from the 2021 updated search process. Two duplicate papers were dropped, and two papers were added from handsearching. Furthermore, five ineligible articles were dropped after reading the full-text manuscript. Thus, eleven articles were included, comprising three systematic reviews with meta-analysis (SR-MA), three SR without MA, and five observational studies.

All articles were appraised for validity, importance, and applicability using the critical appraisal tools from the Centre for Evidence-Based Medicine (CEBM), Oxford University for SR and MA, ${ }^{17}$ and the Joanna Briggs Institute (JBI), University of Adelaide appraisal tools for the observational studies. ${ }^{18}$ All papers were reviewed independently by the authors and approved by all contributors through discussions.

Regarding ethical issues, the Declaration of Helsinki stated that formal ethical approval might not be necessary in case reports, and no experiments were performed on subjects. We have obtained consent and permission from the patient to publish her case without disclosing the institution and her identity.

\section{RESULTS}

To establish etiology, we attempted to get research studies that stated odds ratio (OR), relative risk (RR), or injury hazard ratio (IHR). In this EBCR, eleven etiological studies were obtained and suitable for the clinical question. Still, most studies on this topic only disclosed a measure of risk as significant correlation or relative proportion between night shift and day shift or afternoon shift.

Based on the critical appraisal for validation of the six SR and MA studies in Table 1, two studies (Litwiller B et al. and Kucharczyk ER et al.) did not explicitly include the specific clinical question. ${ }^{19,20}$ Still, a similar PEO was implicitly drawn from the summary table. A meta-analysis from Litwiller B et al. did not include forest plots or heterogeneity analysis found on typical MA. ${ }^{19}$ Studies from Litwiller B et al., Kucharczyk ER et al., Whelehan DF et al., Gates M et al., did not include all high-quality studies probably because research related to sleep deprivation among workers was minimal and were primarily observational studies, with a level of evidence between III to IV. ${ }^{19,21,22}$

Research from Whelehan DF et al., Di Muzio M et al. (a)., and Kucharczyk ER et al. did not apply to heterogeneity analysis because no meta-analysis was done for the data. ${ }^{20,21,23}$ The SR and MA from Wagstaff AS et al. was a high-quality study and provided risk outcomes in the form of odds ratio $(\mathrm{OR})$, risk ratio (RR), and injury hazard ratio (IHR) for an occupational-related accident. ${ }^{24}$

Another type of study obtained was observational studies, which have been critically appraised, and the results are shown in Table 1.

Only Cho SS et al. did not clearly define the sample inclusion criteria among the five observational studies. This study included workers in general, not limited only to healthcare professionals. ${ }^{25}$ The paper was still eligible because other items were considered valid. Three studies, Di Muzio $\mathrm{M}$ et al. (b)., Cho SS et al., and Ganesan S et al., stated possibly confounding factors without controlling them but recommended adjustments for further research. ${ }^{25-27}$ In short, all eleven studies were considered valid with a middle level of evidence (level III-IV). ${ }^{28}$

The articles were critically reviewed for the aspect of importance, which is summarized in Table 2. The papers were all clinically meaningful, even though some of the results were not statistically significant. An outline of the outcomes in each article is shown in Appendix A.

The applicability assessment for all studies is explained in Table 1. Overall, the studies were applicable to our study population. However, five studies were not similar to our clinical scenario, and we marked them as unclear. For example, these studies by Whelehan DF et al. and Gates M et al. focused on doctors as the studied population; Litwiller $\mathrm{B}$ et al. did not list specifically the workers' population; Kucharczyk ER et al. included various other people as part of the study. ${ }^{19-22}$ Another issue was from a study by Cho SS et al., ${ }^{25}$, which only stated the study population as general workers (including healthcare professionals). To overcome this issue, we only included the outcomes from relevant studies in their summary table, particularly studies that use the term "general workers" and have health workers as part of their study population.

In short, the eleven studies were eligible for review on the impact of sleep deprivation on work performance among healthcare night shift workers, and we furthermore constructed the best recommendation for the patient in this case report.

\section{DISCUSSION}

\section{Analysis of Case}

In this case report, our diagnosis for Mrs. A was sleep deprivation (ICD-10-CM Code Z72.820) both qualitatively and quantitatively. ${ }^{19}$ Her sleep quantity decreased due to the night shift schedule, which dramatically reduced her sleep 
Table 1. A critical appraisal of the validity and applicability of a systematic review with meta-analysis and observational studies included

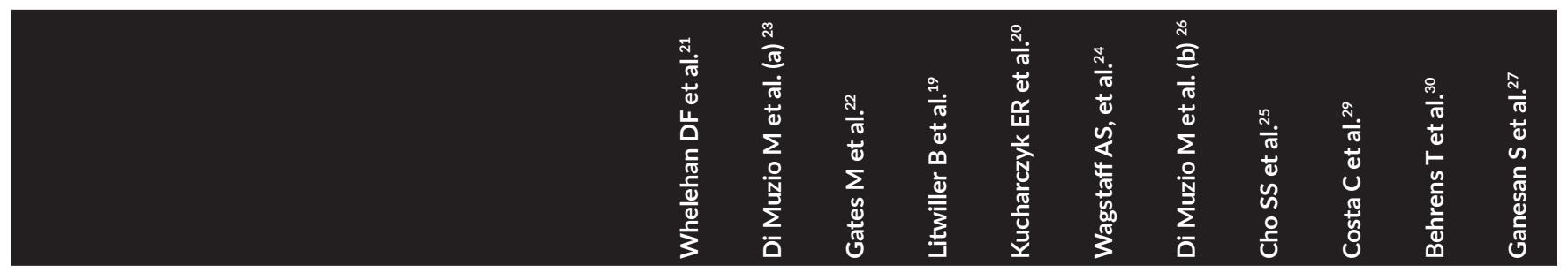

CA for Validity of SR and MA studies ${ }^{\mathrm{a}}$

1. Clearly defined PEO
2. All relevant evidence found
3. Appropriate inclusion and exclusion criteria
4. Valid and relevant studies are assessed
5. Inclusion of high-quality and low-risk of bias studies
6. Summary table or plot to total up the result
7. Heterogeneity analysis

CA for Validity of Observational studies ${ }^{b}$

1. Clearly defined sample inclusion criteria

2. Detailed description of subjects and setting

3. Valid and reliable measurement of exposure

4. Standard criteria for disease/ injury measurement

5. Identification of confounding factors and dealt with

4. Valid and reliable measurement of outcome

\begin{tabular}{|c|c|c|c|c|c|c|c|c|c|c|c|}
\hline CA for Applicability of All studies s,b & & & & & & & & & & & \\
\hline 1. Similarity of Patients & O & 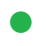 & O & O & O & 0 & 0 & O & 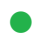 & 0 & 0 \\
\hline 2. Clinically Important Outcome & ○ & - & ○ & ○ & - & ○ & ○ & ○ & - & ○ & - \\
\hline 3. Beneficial to My Patient & - & - & 0 & 0 & - & - & 0 & - & - & ○ & 0 \\
\hline
\end{tabular}

3. Beneficial to My Patient

${ }^{a}$ Checklist from Oxford CEEBM; ${ }^{b}$ Checklist from JBI.

Abbreviation: CA (Critical Appraisal); MA (Meta-Analysis); PEO (P: patient, population, problem; E: exposure; O: outcome); SR (Systematic Review). Notes: Yes, clearly stated in the study: Unclear/ Not applicable/ Variable result: No, definitely not matched with the criteria:

hours and changed her sleep pattern. In terms of quality, her sleep deprivation was proven by symptoms of feeling sleepy while working, failing to fall asleep, and feeling not refreshed when waking up in the morning, although adequate hours of sleep were met. ${ }^{19}$ In fact, nurses have two kinds of shift work settings, specifically 3 -shifts or 2-shifts work settings. Sleeping deprivation in nurses occurred in around $30-70 \%$ of nurses in 3-shifts work, setting an average sleep duration of 6.8 hours, while in a 2 -shifts work setting, the sleep duration was 5.2 hours. $^{31-34}$ Thus, nurses, as one of the categories of health workers on the night shift, would be having less time to sleep than in other types of shifts, either in quality or quantity. ${ }^{19}$

Mrs. A also complained of dizziness, decreased concentration, heartburn, and lethargy, which probably were a cumulative physiological manifestation of sleep deprivation. ${ }^{35,36}$ She thought this issue would continuously influence her performance, proven by the incidence of needle stick injury during her duty, which fortunately did not affect blood-borne disease transmission based on interim laboratory results. Her medical history and the general physical examination have excluded any psychological problems, the background of psychiatry disease, and comorbidities. In this patient, what needed to be considered was her BMI, which was classified as obese, which was also a manifestation of metabolic and endocrine changes from lack of sleep. ${ }^{35,36}$

Based on our examination, Mrs. A had acute anxiety as observed from her physiological tachycardic reflex. In addition, she worried her sleeping problem could interfere with her performance in the hospital. Therefore, we searched relevant evidence-based research designs (SR, MA, and observational studies) to investigate these issues that matched the etiologic clinical question type.

\section{Importance of the Reviewed Studies}

We successfully attained eleven relevant articles to answer our patient's question, comprising six SRs with/without MA and five observational studies. Among the six SR-MAs, SR of Whelehan DF et al. has a brief explanation about the impact of sleep deprivation on the technical skill proficiency of surgeons as one of the key personnel to maintain patient safety during operation. ${ }^{21}$ There was an $11.9-32 \%$ decrease in performance, which could impact the patient's safety. Previous studies also showed that sleep deprivation caused 
Table 2. The summary findings of the importance of studies included related to the effects of sleep deprivation on work performance

\begin{tabular}{|c|c|c|c|c|c|}
\hline Authors & LoE & Study design & Population & $\begin{array}{l}\text { Measure } \\
\text { of risk }\end{array}$ & Effects of Sleep Deprivation \\
\hline $\begin{array}{l}\text { Whelehan } \\
\text { DF et al. }{ }^{21}\end{array}$ & $3 \mathrm{~A}$ & $\begin{array}{l}\text { SR with MA } \\
\text { of OS }\end{array}$ & Surgeons & p-value & $\begin{array}{l}\text { - Probably worsen technical proficiency skills. } \\
\text { - Decreased performance not statistically significant (11.9-32\%). }\end{array}$ \\
\hline $\begin{array}{l}\text { Di Muzio M } \\
\text { et al. (a) }{ }^{23}\end{array}$ & $3 \mathrm{~A}$ & SR of OS & Nurses & $\begin{array}{l}\text { OR and } \\
\text { p-value }\end{array}$ & $\begin{array}{l}\text { - Increased risk of accidents and medication error (error rates } 2-4 \% \text { and } \\
\text { OR 2) and increased patients' death by } 300 \% \\
\text { - Impaired communication skill with patients and team } \\
\text { - Disturbed sleep (56\% sleep-deprived) and resulting fatigue } \\
\text { - Impaired cognition and correlated with safety }\end{array}$ \\
\hline
\end{tabular}

\begin{tabular}{|c|c|c|c|c|c|}
\hline $\begin{array}{l}\text { Gates M } \\
\text { et al. }{ }^{22}\end{array}$ & $3 A$ & $\begin{array}{l}\text { SR with MA } \\
\text { of OS }\end{array}$ & Doctors & $\begin{array}{l}\text { OR, MD, } \\
\text { and }\end{array}$ & $\begin{array}{l}\text { - These factors are related to health and well-being: increased burnout } \\
\text { (OR 0.84), elevated parameters of biochemical or physiological stress }\end{array}$ \\
\hline
\end{tabular}

p-value related to work ( $p<0.05)$, enhanced odds of using tobacco (OR 1.42), and tranquilizer use (OR 3.26), and odds of sickness (OR 2.92). Sleep deprivation is correlated with thoughts of suicide $(p<0.01)$, mood disturbances $(p<0.001)$, and depression (OR 2.38-2.70). Life, job, marital satisfaction decreased (OR 0.44), and life-balanced perception worsened (OR 0.46).

- Related to performance and risk of errors: no influence in surgery time and efficiency (MD -0.14; $p=0.70$ ) and no impact to laparoscopic simulation skill; but disrupted performance on a virtual ring transfer task $(p<0.05)$, made longer reaction times, and reduced concentration ability. In addition, there was reduced HVLT among anesthesiologists-reduced reaction time after sleep deprivation was found $(p<0.05)$.

- Related to the patient and occupational safety: increased medical and prescribing error (RR 1.25), but did not result in a difference in the rate of postoperative complications and mortality (RR 0.98).

\begin{tabular}{|c|c|c|c|c|}
\hline $\begin{array}{l}\text { Litwiller B } \\
\text { et al. } 16\end{array}$ & $3 A$ & $\begin{array}{c}\text { SR with MA } \\
\text { of OS }\end{array}$ & $\begin{array}{c}\text { General and } \\
\text { health workers }\end{array}$ & $p$-value \\
\hline
\end{tabular}

- Sleep quality and quantity are associated significantly, and they are negatively correlated with: (1) state negative affect; (2) turnover cognition; (3) job satisfaction; (4) task performance; (5) contextual performance; and (6) safety performance.

Kucharczyk 3A SR of OS General and p-value - Sleep disturbances in the night-shift worker cause: (1) lowered job ER et al. ${ }^{15} \quad$ health workers satisfaction $(p<0.01)$; decreased workplace productivity $(p<0.01) ;(3)$ increased work disability $(p<0.001)$; (4) increased desire to change career and more likely will slow career progression ( $p<0.01)$; (5) enhanced the odds of absenteeism $(p<0.01$ to $p<0.05)$; and (6) elevated the odds of work accidents $(p<0.05)$.

\begin{tabular}{|c|c|c|c|c|c|}
\hline $\begin{array}{l}\text { Wagstaff AS } \\
\text { et al. }{ }^{14}\end{array}$ & $3 A$ & $\begin{array}{l}\text { SR with MA of } \\
\text { OS. }\end{array}$ & $\begin{array}{l}\text { Nurses and other } \\
\text { health workers }\end{array}$ & $\begin{array}{l}\text { IHR, OR, } \\
\text { and RR }\end{array}$ & $\begin{array}{l}\text { - Night shift and sleep deprivation increased the odds of work-related } \\
\text { injuries with IHR 1.30; } 95 \% \mathrm{Cl}: 1.12-1.52 \text {. }\end{array}$ \\
\hline $\begin{array}{l}\text { Di Muzio M } \\
\text { et al. (b) }{ }^{26}\end{array}$ & $2 \mathrm{C}$ & $\begin{array}{l}\text { Cross-sectional } \\
\text { study }\end{array}$ & Nurses & $\mathrm{p}$-value & $\begin{array}{l}\text { - Tiredness was greater after the night shift worker }(p<0.001) \text {. } \\
\text { - Sleepiness was higher in the night shift worker }(p<0.001) \text {. } \\
\text { - Response times were higher in the night worker }(p<0.001) \text {. } \\
\text { - Lapses in the night shift were greater }(p<0.05) \text {. }\end{array}$ \\
\hline $\begin{array}{l}\text { Cho SS } \\
\text { et al. }{ }^{25}\end{array}$ & $2 \mathrm{C}$ & $\begin{array}{l}\text { Cross-sectional } \\
\text { study }\end{array}$ & $\begin{array}{l}\text { General and } \\
\text { health workers }\end{array}$ & HRPL & $\begin{array}{l}\text { - Fixed night work significantly reduced } 7.7 \% \text { of productivity }(95 \% \mathrm{Cl} \text { : } \\
1.8-13.7) \text {. }\end{array}$ \\
\hline $\begin{array}{l}\text { Costa C } \\
\text { et al. }{ }^{29}\end{array}$ & $2 \mathrm{C}$ & $\begin{array}{l}\text { Cross-sectional } \\
\text { study }\end{array}$ & $\begin{array}{l}\text { Residents } \\
\text { (Doctors) }\end{array}$ & $\mathrm{p}$-value & $\begin{array}{l}\text { - No daytime sleepiness, sleep disorders, intellectual efficiency changes, } \\
\text { and cognitive impairment were found significantly after a night shift, but } \\
\text { it negatively impacted moods and daily activity. }\end{array}$ \\
\hline $\begin{array}{l}\text { Behrens T } \\
\text { et al. }{ }^{30}\end{array}$ & $2 \mathrm{C}$ & $\begin{array}{l}\text { Cross-sectional } \\
\text { study }\end{array}$ & $\begin{array}{l}\text { Nurses and } \\
\text { medical lab } \\
\text { assistants }\end{array}$ & $\begin{array}{l}\text { Beta } \\
\text { logistic } \\
\text { models }\end{array}$ & $\begin{array}{l}\text { - In night shift worker, reaction times were increased }(\beta=7.64 ; 95 \% \mathrm{Cl} \text { : } \\
0.94-14.35) \text {; number of lapses were higher }(\exp (\beta)=1.55 ; 95 \% \mathrm{Cl} \text { : } \\
\text { 1.16-2.08); and index of response speed and accuracy was reduced } \\
\text { after night shifts }(\beta=-15.52 ; 95 \% \mathrm{Cl}-27.49-(-3.46))\end{array}$ \\
\hline $\begin{array}{l}\text { Ganesan S } \\
\text { et al. }{ }^{27}\end{array}$ & $2 \mathrm{C}$ & $\begin{array}{l}\text { Cross-sectional } \\
\text { study }\end{array}$ & $\begin{array}{l}\text { Doctors and } \\
\text { nurses }\end{array}$ & p-value & $\begin{array}{l}\text { - Restricted sleep }(5.74 \pm 1.30 \mathrm{~h} ; \mathrm{p}<0.001) \text { in night shift. } \\
\text { - Delayed time of waking up in night shift worker }(p<0.001) \text {. } \\
\text { - PVT mean reaction times were higher }(p<0.001) \text {. } \\
\text { - Increased sleepiness and drowsiness }(p<0.01) \text {. }\end{array}$ \\
\hline
\end{tabular}

Abbreviation: 95\% CI (95\% Confidence Interval); HRPL (Health-Related Productivity Loss); HVLT (Hopkin's Verbal Learning Test); IHR (Injury Hazard Ratio); LoE (Level of Evidence); MA (Meta-Analysis); MD (Mean Difference); OR (Odd ratios); OS (Observational Studies); PVT (Psychomotor Vigilance Task); RR (Relative Risk or Risk Ratio); SR (Systematic Review). 
decreased attention, vigilance, and precision, correlated to skill performance. ${ }^{21,37,38}$ It was also worsened by impaired information processing and delayed decision-making as the brain's cognitive and psychomotor aspects. But the reason that the skill decreased in this study was not statistically significant might be evidence that sleep loss only impaired performance in simple tasks instead of complex cognitive tasks like surgery. Therefore experts in surgery might easily handle sleep disturbance based on their expertise. ${ }^{21}$

The SR of Di Muzio M et al. (a) analyzed the impact of sleep deprivation on the working performance of nurses, focusing on the risk management and occurrence of medication errors. ${ }^{23}$ Several essential factors in this paper included increased workload and fewer personnel, commonly found during the night shift, resulting in significant errors due to fatigue. Sleep deprivation during the night shift also could impair the communication skills of the patient, family, and team. It could also result in cognitive dysfunction, which potentially affects the patient and their safety. ${ }^{23}$ The limitation of this SR was the inevitable heterogeneity of studies, some of which did not state their OR, RR, or HR. Similar limitations were likewise described in the study by Whelehan DF et al. ${ }^{21}$

The SR with MA from Gates M et al. explained that fatigue and sleep deprivation could reduce physicians' well-being and work-life satisfaction, increasing chances of burnout, depression, and psychological stress..22 Several studies also mentioned that sleep deprivation caused longer reaction time in psychomotor aspects and the likelihood of medication errors. However, analysis of studies included in this MA revealed that fatigue and sleep deprivation did not result in prolonged operation time or increased patient mortality and postoperative complications. ${ }^{22}$

A MA study by Litwiller B et al. stated a correlation between sleep quality and quantity. ${ }^{19}$ Both of them have some impacts on work performance towards workers, such as mental health correlates, i.e., increased anxiety, depression, fatigue, and general strain; turnover cognition and negative affective state (reduction of the accuracy to recognize others' emotions); and correlation between sleep deprivation to work performance such as job satisfaction, task performance, contextual performance, and safety performance. ${ }^{19}$ This study had good outcomes but not in the form of OR, RR, or HR. ${ }^{19}$

An SR study done by Kucharczyk ER et al. stated that sleep disturbances are associated with lower job satisfaction, reduced productivity, slower career progression, increased risk of absenteeism, and workplace accidents. ${ }^{20}$ However, some limitations of Kucharczyk ER et al. were (1) the lack of information about the quality of studies included in their paper; (2) heterogeneity and different operational definitions of included studies; (3) the lack of OR or RR, with the only association value measured by $\mathrm{p}$-value, which concluded causation challenging to obtain. ${ }^{20}$

This lack of data limited the conclusion only to the association between night shift work manifested in sleep deprivation and work performance. Still, it could not explain the causal order of these factors. Following job satisfaction, there was evidence that fatigue in the nurse population contributed to job dissatisfaction and made them retire from the profession. ${ }^{39-42}$ The rate of turnover cognition or thinking of quitting for nurses in the United States of America was impactful for hospital cost, about 27\%, ranging from 5-27 million USD per year. ${ }^{43}$

The SR and MA from Wagstaff AS et al. was a highquality study, proving that long working hours are associated with an increased risk of a work-related accident. ${ }^{24}$ This study provided several measurement outcomes (OR, RR, and IHR). However, some of the studies included used selfreported data, which could potentially cause bias. Also, the authors only had English journals which potentially can cause publication bias. ${ }^{24}$ Study from Gates $\mathrm{M}$ et al. and $\mathrm{Di}$ Muzio M et al. (a) were the two best studies among SR and MA, which matched our clinical question and have clinical importance to be applied. ${ }^{22,23}$

Di Muzio $M$ et al. (b) compared the impact of night, morning, and afternoon/evening shifts on nurses' psychomotor performance, tiredness, and sleepiness in the observational studies. ${ }^{26}$ They found that nurses at the end of their night shift were sleepier and more tired than those on day shift. Furthermore, the night shift nurses' performance on the Psychomotor Vigilance Task (PVT) was worse than the day shift. The nurses' lower performance on the PVT could be associated with a higher risk of medical errors. ${ }^{26}$ Although no studies directly evaluated the correlation between PVT performance and medical errors, some studies found that mistakes in the workplace could be predicted due to reduced sustained attention. ${ }^{44,45}$

Cho SS et al. ${ }^{25}$ conducted a cross-sectional study in young adult workers aged 19 and above in South Korea. This study involved a total of 4,146 workers assessing whether there is a significant role of work-shift in reducing productivity. The questionnaire was used as a data source and resulted in only a fixed night-shift work schedule significantly reduced $7.7 \%$ points of productivity (95\% CI: $1.8-13.7$ ).

In Italy, with 80 medical residents, Costa $\mathrm{C}$ et al. ${ }^{29} \mathrm{did}$ a cross-sectional study with four questionnaires. The results showed no cognitive impairment, daytime sleepiness, and sleeping disorders among the residents. However, it turns out that there were emotional problems within the residents that impact work performance..$^{29}$

A more complex assessment of sleep deprivation's psychomotor impact was described in Behrens $\mathrm{T}$ et al. ${ }^{30}$. This research compared PVT in female health workers after their day and night shifts. After the night shift, they found that the workers' reaction times increased, and the number of lapses after the night shift was higher than the day shift. The result of this study was similar to other previous studies, which found that the nurses' PVT-response speed ${ }^{46}$ and reaction times decreased at night shift compared to nurses of the day shift. ${ }^{47}$ However, this study found that 
the number of lapses was reduced after the third night shift indicating an adaptation of the workers to the night shift schedule, which is also found in the previous similar study. ${ }^{48}$

The fifth observational study from Ganesan $\mathrm{S}$ et al. ${ }^{27}$ involved 52 doctors and nurses aged 22-64 in Australia given an online questionnaire, and also a record of their sleep-wake behavior with a wrist-worn actigraph and daily sleep diary, assessing them with Karolinska Sleepiness Scale (KSS) and 5 minutes visual PVT, and testing their drowsiness with John Drowsiness Scale (JDS). The result showed that sleep was mainly restricted during consecutive night shifts. The PVT and KSS scores were both poorer when working on night shifts. Performances both in the first night shift and the following night shifts were all impaired. ${ }^{27}$

\section{From Basic Science of Sleep Deprivation to Occupational Impacts}

In exploring the basic science regarding the link between sleep deprivation among night shift workers and occupational impacts, a causal pathway was revealed, as illustrated in the framework of relationships between work and sleep in Figure 2. Existing studies still connect the night shift with a reduction in sleep in terms of quantity and quality. Thus, sleep deprivation will manifest into an exhausted condition that can interfere with information processing and affective responses to potentially cause occupational impact for workers. Twenty-three aspects of work performance are successfully identified, worsening due to sleep deprivation among night shift in healthcare. However, three results had no correlation and impact from sleep deprivation due to the proficiency and expertise of healthcare professionals (particularly surgeons and obstetricians-gynecologist) to keep and maintain their patients' care. All of the essential points were summarized into the conceptual framework in Figure 2. ${ }^{49}$

\section{Sleep Deprivation: Quality and Quantity}

Sleep is defined as the status of immobility characterized by significant deprivation of physical responsiveness of a person and may cause reorganization of neural activity. ${ }^{54,55}$ Sleep has two components, quality and quantity. The key indicators of good sleep quality are having sleeping more time while in bed (at least $85 \%$ of the total time), falling asleep in 30 minutes or less, waking up no more than once per night; and being awake for 20 minutes or less after initially falling asleep. ${ }^{54,55}$ Meanwhile, good sleep quantity is defined by age. For adults (26-64 years old), proper sleep quantity ranges from 7-9 hours, and a length less than 6 hours or more than 10 hours is not recommended. ${ }^{56}$

A person may be sleep-deprived both qualitatively and quantitatively. Both of them are significantly correlated with each other. ${ }^{19}$ Sleep quality deprivation is subjectively referred to as fatigue after waking up and may continue during the day, sleepiness after resting, and frequently waking up at night. ${ }^{19}$ Problems of sleep quality can be encountered in both people with enough sleep duration and insomnia. Deprivation of quality and quantity of sleep affects longterm cognitive performance, motoric function, mental health, and physical health of workers. All of these effects may reduce the work performance of a worker. ${ }^{19}$

\section{Association between Sleep Deprivation and Occupa- tional Impact: Analysis of Physiological Changes}

Sleeping is controlled by a circadian rhythm with a 24hour endogenous rhythm through daily exposure to light and dark cycles. Specifically, circadian rhythm is regulated by the melatonin hormone and the suprachiasmatic nuclei (SCN). As a diurnal species, melatonin is hypnogenic (inducing sleep or hypnotic state) for humans. The SCN influences clocks in peripheral tissues through neural signals communicated via the autonomic nervous system (ANS). Artificial light exposure at night can disrupt the SCN clock and melatonin rhythm. ${ }^{57-59}$ By lacking sleep at night, the circadian rhythm will present an alertness phase until the worst sleepiness occurred in the morning. ${ }^{60}$

Sleepiness significantly impacts work outcomes through physiological changes towards information processing, cognitive, affective, motoric function, and mental and physical health. In information processing, losing 24 hours of sleep will result in the deactivation of $7 \%$ of the area in the brain, as proved by glucose hypometabolism. The most impacted area of the brain would be the prefrontal cortex, temporal, superior-parietal inferior part of the brain, and the thalamus. ${ }^{35,36}$ The prefrontal cortex controls high cognitive functions, such as planning, foresight, and problem-solving. ${ }^{61}$ The temporal-inferior superior parietal cortex is responsible for other higher cognitive abilities such as semantic hearing and visual information processing. ${ }^{61}$ Thalamus generally controls arousal. Thus, sleepiness causes hypometabolism in the area of the brain responsible for higher regulation of cognitive abilities and arousal. ${ }^{35,36,61}$

In cognitive function, short-term sleep deprivation can reduce the speed and accuracy of simple attention, complex attention, working memory, processing speed, short-term memory, and reasoning skill. ${ }^{62}$ Sleep deprivation produces a decrease in the speed of information processing shown by the slower response time, increased errors, and decreased ability to correct the mistakes. ${ }^{63}$ Sleep deprivation generally negatively affects attention and selectivity, with a more significant deficit in the early stage of cognitive processing (e.g., visual processing) than in the later stages (e.g., response selection). ${ }^{64}$ Sleep deprivation has been found to reduce the function of memory by reducing hippocampus activity. Thus, even one night of sleep loss will interfere with someone's work, memory, and learning processes that depend on the hippocampus.

Sleepiness also impairs affect and emotional recognition because of decreased metabolic activity in the corticolimbic pathway. A decrease in metabolic activity in the prefrontal brain area with reduced inhibitory input to the limbic 


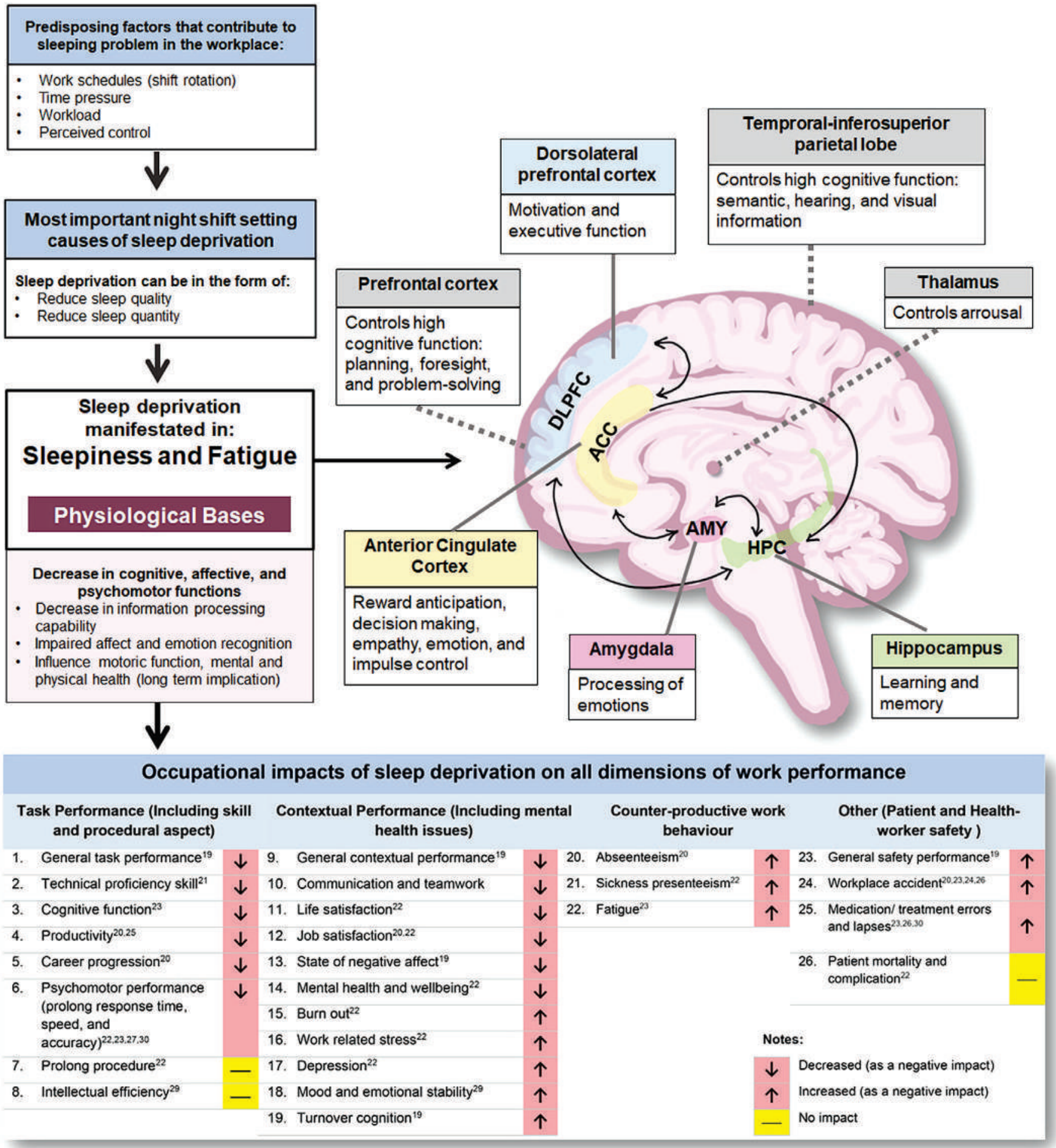

Figure 2. The proposed framework of relations among sleepiness, its manifestations, and its antecedents. ${ }^{19-27,29,30,35,36,49-53}$

system likely contributes to increased emotional activation of the amygdala and declines in sleep. ${ }^{51}$ Therefore, drowsy people will lose the capability of work, memory, and learning processes that depend on the hippocampus. People with sleep deprivation are more easily distracted by negative emotional stimuli and more likely to choose based on emotional feelings. ${ }^{65}$ These effects have been linked to a decrease in connectivity between the amygdala and the prefrontal cortex and reduced inhibitory input to the amygdala. ${ }^{52}$

In the mental health aspect as an integral part of work, it is also seen that both sleep quantity and quality disturbances significantly correlated to depression, fatigue, and general 
stress. The association value was more significant in sleep quality compared to quantity. ${ }^{64}$

\section{Occupational Impacts}

It is known that sleepiness caused by sleep deprivation in workers potentially affects their work, primarily through physiological changes that manifested into information processing and affective disorders. Affective and cognitive function is often used as task performance predictors. ${ }^{62}$ Evidences in Table 2 shows that sleep quality or sleep quantity deprivation was associated with work performance dimensions, comprising task performance, contextual performance (including mental health issues), counterproductive work behavior, and work-related safety issues. ${ }^{49}$ Task performance is the core job responsibility of an employee, which refers to the effectiveness with which job incumbents contribute to the organization's technical, service process, and production of goods. ${ }^{60}$ Contextual performance is defined as the contextual work behavior that supports the work environment, ${ }^{62}$ it includes emotional, communication, and mental health issues of the worker in the workplace. ${ }^{49}$ The definition of counterproductive work behavior refers to behavior that is harmful to the well-being of the institution or work organization. ${ }^{66}$ After the three dimensions, we add another dimension which is work-related safety, including patient or health worker safety, because it should be recognized as an essential dimension of work performance in healthcare setting. ${ }^{53}$

The impact of sleep deprivation or poor sleep quality on work performance is various. The appraised SR shows that the effects of poor sleep quality are associated with absenteeism, poor work productivity (efficiency and competency), slowed career progression, and low job satisfaction..$^{20}$ The same SR states that most reviewed studies showed an increased risk of a severe or non-serious workplace accident. ${ }^{20}$ In addition, another research showed that sleep deprivation is associated with car accidents, work-related injury, work injury, fatigue, related error, near-miss incidents, and other serious errors. ${ }^{24}$

\section{Recommendations for Patient}

In response to the negative impact of sleep deprivation to work performance because of night shift work, we encourage our patients and other health workers to adjust shifts properly. Hospital management should reevaluate the issue of tiredness in the workplace. Employees should ensure sound sleep quality by keeping the practice of sleep hygiene. Other recommendations include appropriate scheduling, adequate staff recruitment, better organization of staff, education and health promotion about sleep deprivation, and better consideration of sleep deprivation as contributing factors to medical errors. Medical staff also can be suggested to use breaks while working for naps and consume the appropriate amount of caffeine to be alert while on duty ${ }^{67,68}$ However, caffeine should be taken in moderation. It is allowed to take low doses of caffeine (maximum dose of $4 \mathrm{mg} / \mathrm{kg}$ ) admi- nistered at $12.20 \mathrm{am}$ and $01.20 \mathrm{am}$, which effectively decreases sleep tendency on the night shift, improve performance, and did not disrupt daytime sleep in the morning. ${ }^{69,70}$

Concerning the nurse population, the clockwise shift rotation (day-evening-night) is preferable to maintain health rather than counterclockwise rotations. Based on the evidence, 8 -hour shifts are preferred over 12 -hour shifts. ${ }^{71}$ The best arrangement of shift rotation schedule is from the French system. The rotational schedule should include no more than 3 -night shifts in a block with three days of recovery after the night shift. In one block, a worker will get three mornings, three evenings, three nights, and three recuperative days off (e.g., working $8 \mathrm{am}$ to $4 \mathrm{pm}$ for three shifts; then $4 \mathrm{pm}$ to 12 am for three shifts; and 12 am to 8 am for three shifts; then three consecutive days offs). ${ }^{70,72}$ Also, it is recommended to slowly rotate the schedule (e.g., three weeks on each shift before a change is instituted) for better circadian adaptation.

Meanwhile, the recommendation for a physician who has a 12-hours shift system are (1) do not make the physician a becoming 24-hours shift worker in the early phases of adaptation, (2) delegate the authority to the greatest extent possible while taking a break to sleep, (3) if the staff is limited and it is not possible to for the system to become an eight hour-shift system, a maximum of 10-hour long shifts are allowed, followed by three recuperative days. ${ }^{70}$ (4) Night shift doctor should consider that after working a night shift in a rotational schedule, adequate recovery time must be needed, which is at least three days. ${ }^{69}$ The way to minimize circadian disruption is by using anchor sleep which means the overlapping time - at least 4 hours - during the same timeframe on the workers' workdays and off days are used to sleep. For example, if the workers are discharged from night shift duty, they should sleep from 9 am to $5 \mathrm{pm}$, then wake up before sleeping again from 5 am to $1 \mathrm{pm}$ on days off; the overlapping interval from $9 \mathrm{am}$ to $1 \mathrm{pm}$ is anchor sleep..$^{70,73}$

In addition, the most relevant recommendation is the improvement of the physical fitness of workers, along with consumption of high nutritional food in the workplace to maintain the health and sleep quality of workers, because both are positively correlated with productivity and reduce absenteeism among employees. ${ }^{74}$ Moreover, our patient is in a condition of obesity, so she should maintain nutritional intake and exercise regularly to decrease her BMI and indirectly improve her work performance and well-being.

\section{CONCLUSION}

In conclusion, night shift and sleep deprivation correlate work performance, mental health, productivity, and psychomotor and cognitive ability among healthcare workers. In addition, sleep deprivation is associated with accidents, injuries, fatigue, and other work-related errors. Therefore, our patients should be aware of their shift schedules and practice a healthy lifestyle to maintain productivity. In terms of limitations, the difficulties in making this EBCR are the lack 
of studies that provide outcome measurement in the form of odds ratio, relative risk, or hazard ratio, and most of the studies only stated $\mathrm{p}$-value between working in the night shift to work performance, which leads to complications in assessing the magnitude of the causal effect. Also, we cannot evaluate potential confounding factors in the relationship between night shift, sleep deprivation, and work performance. In addition, there is a difference in the operational definition of work performance and sleep adequacy in each study, making it difficult to get a firm conclusion. In addition, we mainly found literature with a medium level of evidence (level IIIIV) in most of our studies because most studies are observational studies in the lower level of the pyramid of evidence compared to clinical trials. Further studies, especially on the population directly impacted by night shifts, are necessary for other discussions on this topic.

\section{Statement of Authorship}

$\mathrm{MH}$ conceptualized the case report, performed the clinical examination, collected clinical data, searched and reviewed the literature, designed the figures and tables, and made a significant contribution to the writing of the manuscript.

EL, FH, and NG searched and reviewed the literature and made a substantial contribution to the report of the manuscript.

LTM performed the clinical examination, releasing medical record data, reviewed the manuscript.

$\mathrm{MH}, \mathrm{EL}, \mathrm{FH}, \mathrm{NG}$ performed the paper review and editing of the manuscript.

Finally, LTM did the final review. All authors have read and approved the final version of the manuscript.

\section{Author Disclosure}

All authors declared no conflicts of interest.

\section{REFERENCES}

1. International Labour Organization. World Employment And Social Outlook: Trends 2020 [Internet]. 2020 [cited 2021 Mar 19]. Available from: https://www.ilo.org/global/research/global-reports/ weso/2020/lang--en/index.htm

2. International Labour Organization. Asia - Pacific Employment and Social Outlook [Internet]. 2020 [cited 2021 Mar 19] Available from: https://www.ilo.org/asia/publications/WCMS_764084/lang--en/ index.htm

3. World Health Organization. Global strategy on human resources for health: Workforce 2030 [Internet]. 2016 [cited 2021 Mar 19]. Available from: https:/www.who.int/hrh/resources/globstrathrh-2030/en/

4. International Labour Organization. Productivity [Internet]. 2015 [cited 2021 Mar 19]. Available from: https://www.ilo.org/global/ topics/dw4sd/themes/productivity/lang--en/index.htm

5. International Labour Organization. World Statistic: The enormous burden of poor working conditions [Internet]. 2003 [cited $2021 \mathrm{Mar}$ 19]. Available from: https://www.ilo.org/moscow/areas-of-work/ occupational-safety-and-health/WCMS_249278/lang--en/index.htm

6. Magnavita N, Garbarino S. Sleep, Health and Wellness at Work: A Scoping Review. Int J Environ Res Public Health. 2017 Nov; 14(11): $1-5$.

7. Makary MA, Daniel M. Medical error-the third leading cause of death in the US. BMJ. 2016 May;353:i2139.
8. World Health Organization. Protecting workers' health [Internet]. 2017 [cited 2021 Mar 19]. Available from: https://www.who.int/news$\mathrm{room} /$ fact-sheets/detail/protecting-workers'-health

9. Päivi Hämäläinen JT\& TBK. Global Estimates of Occupational Accidents and Work-related Illnesses 2017. Work Saf Heal Institute, Finl. 2017;1-21.

10. Company SMI. Occupational injuries in health care [Internet]. sfmic. com. 2020 [cited $2021 \mathrm{Mar}$ 19]. Available from: https://app.sfmic. $\mathrm{com} / \mathrm{col} /$ resourceCatalog/Doc/health-care-injuries-infographic-factsheet.pdf

11. Luckhaupt SE, Tak S, Calvert GM. The prevalence of short sleep duration by industry and occupation in the National Health Interview Survey. Sleep. 2010 Feb;33(2):149-59.

12. Giorgi F, Mattei A, Notarnicola I, Petrucci C, Lancia L. Can sleep quality and burnout affect the job performance of shift-work nurses? A hospital cross-sectional study. J Adv Nurs. 2018 Mar;74(3):698-708.

13. Guimarães CA. Evidence based case report. Rev Col Bras Cir. 2015;42(5):280.

14. Godlee F. Applying research evidence to individual patients: Evidence based case reports will help. BMJ. 1998;316:1621-2.

15. Pudjiastuti P.Pengantar Evidence-Based Case Reports [in Indonesian]. Sari Pediatr. 2016;11(6):385.

16. Jones-Harris AR. The evidence-based case report: A resource pack for chiropractors. Clin Chiropr. 2003;6(2):73-84.

17. Oxford for CEEBM. Worksheet for systematic review [Internet]. 2019 [cited 2019 Sep 20]. Available from: https:/www.cebm.net/ wp-content/uploads/2014/06/diy-systematic-review-appraisalworksheet.pdf

18. The Joanna Briggs Institute (JBI), University of Adelaide, South Australia. The Joanna Briggs Institute Critical Appraisal Tools: Checklist for Analytical Cross Sectional Studies [Internet]. 2017 [cited 2021 Mar 19]. Available from: https://joannabriggs.org/sites/default/ files/2019-05/JBI_Critical_Appraisal-Checklist_for_Analytical_ Cross_Sectional_Studies2017_0.pdf

19. Litwiller B, Snyder LA, Taylor WD, Steele LM.The relationship between sleep and work: A meta-analysis. J Appl Psychol. 2017;102(4):682-99.

20. Kucharczyk ER, Morgan K, Hall AP. The occupational impact of sleep quality and insomnia symptoms. Sleep Med Rev. 2012;16(6):547-59.

21. Whelehan DF, McCarrick CA, Ridgway PF. A systematic review of sleep deprivation and technical skill in surgery. Surgeon. 2020; 18(6):375-84.

22. Gates M, Wingert A, Featherstone R, Samuels C, Simon C, Dyson MP. Impact of fatigue and insufficient sleep on physician and patient outcomes: A systematic review. BMJ Open. 2018;8(9):1-12.

23. Di Muzio M, Diella G, Di Simone E, Novelli L, Alfonsi V, Scarpelli S, et al. Nurses and Night Shifts: Poor Sleep Quality Exacerbates Psychomotor Performance. Front Neurosci. 2020;14:1-8.

24. Wagstaff AS, Lie JAS. Shift and night work and long working hours - a systematic review of safety implications. Scand J Work Environ Heal. 2011;37(3):173-85.

25. Cho SS, Lee DW, Kang MY. The association between shift work and health-related productivity loss due to either sickness absence or reduced performance at work: A cross-sectional study of Korea. Int J Environ Res Public Health. 2020;17(22):1-9.

26. Di Muzio M, Dionisi S, Di Simone E, Cianfrocca C, Muzio FDI, Fabbian F, et al. Can nurses' shift work jeopardize the patient safety? A systematic review. Eur Rev Med Pharmacol Sci. 2019;23(10):4507-19.

27. Ganesan S, Magee M, Stone JE, Mulhall MD, Collins A, Howard ME, et al. The Impact of Shift Work on Sleep, Alertness and Performance in Healthcare Workers. Sci Rep. 2019;9(1):1-14.

28. Oxford CEEBM. Oxford Centre for Evidence-Based Medicine: Levels of Evidence (March 2009) [Internet]. Center for EvidenceBased Medicine. 2009 [cited 2021 Mar 19]. Available from: https://www.cebm.ox.ac.uk/resources/levels-of-evidence/oxfordcentre-for-evidence-based-medicine-levels-of-evidence-march-2009

29. Costa C, Mondello S, Micali E, Indelicato G, Licciardello AA, Vitale E, et al. Night shift work in resident physicians: does it affect mood states and cognitive levels? J Affect Disord. 2020;272(2019):289-94.

30. Behrens T, Burek K, Pallapies D, Kösters L, Lehnert M, Beine A, et al. Decreased psychomotor vigilance of female shift workers after working night shifts. PLoS One. 2019;14(7):1-18. 
31. Van Dongen HPA, Maislin G, Mullington JM, Dinges DF. The cumulative cost of additional wakefulness: dose-response effects on neurobehavioral functions and sleep physiology from chronic sleep restriction and total sleep deprivation. Sleep. 2003 Mar;26(2):117-26.

32. Kaliyaperumal D, Elango Y, Alagesan M, Santhanakrishanan I. Effects of Sleep Deprivation on the Cognitive Performance of Nurses Working in Shift. J Clin Diagn Res. 2017 Aug;11(8):CC01-3.

33. Geiger-Brown J, Rogers VE, Trinkoff AM, Kane RL, Bausell RB, Scharf SM. Sleep, sleepiness, fatigue, and performance of 12-hourshift nurses. Chronobiol Int. 2012 Mar;29(2):211-9.

34. Stanojevic C, Simic S, Milutinovic D. Health Effects of Sleep Deprivation on Nurses Working Shifts. Med Pregl. 2016 Oct;69 (5-6):183-8.

35. Mu Q, Mishory A, Johnson KA, Nahas Z, Kozel FA, Yamanaka K, et al. Decreased brain activation during a working memory task at rested baseline is associated with vulnerability to sleep deprivation. Sleep. 2005 Apr;28(4):433-46.

36. Thomas M, Sing H, Belenky G, Holcomb H, Mayberg H, Dannals R, et al. Neural basis of alertness and cognitive performance impairments during sleepiness. I. Effects of $24 \mathrm{~h}$ of sleep deprivation on waking human regional brain activity. J Sleep Res. 2000 Dec;9(4):335-52.

37. Caldwell JA, Caldwell JL, Smith JK, Brown DL. Modafinil's effects on simulator performance and mood in pilots during $37 \mathrm{~h}$ without sleep. Aviat Space Environ Med. 2004 Sep;75(9):777-84.

38. Previc FH, Lopez N, Ercoline WR, Daluz CM, Workman AJ, Evans $\mathrm{RH}$, et al. The effects of sleep deprivation on flight performance, instrument scanning, and physiological arousal in pilots. Int J Aviat Psychol. 2009;19(4):326-46.

39. Barker LM, Nussbaum MA. Fatigue, performance and the work environment: a survey of registered nurses. J Adv Nurs. 2011 Jun;67(6):1370-82.

40. MacKusick CI, Minick P. Why are nurses leaving? Findings from an initial qualitative study on nursing attrition. Medsurg Nurs. 2010;19(6):335-40.

41. Kovner CT, Brewer CS, Fairchild S, Poornima S, Kim H, Djukic M. Newly licensed RNs' characteristics, work attitudes, and intentions to work. Am J Nurs. 2007 Sep;107(9):51-8.

42. Stimpfel AW, Sloane DM, Aiken LH. The longer the shifts for hospital nurses, the higher the levels of burnout and patient dissatisfaction. Health Aff (Millwood). 2012 Nov;31(11):2501-9.

43. Wei H, Sewell KA, Woody G, Rose MA. The state of the science of nurse work environments in the United States: A systematic review. Int J Nurs Sci. 2018 Jul;5(3):287-300.

44. Edkins GD, Pollock CM. The influence of sustained attention on railway accidents. Accid Anal Prev. 1997 Jul;29(4):533-9.

45. Basner M, Rubinstein J. Fitness for duty: a 3-minute version of the Psychomotor Vigilance Test predicts fatigue-related declines in luggage-screening performance. J Occup Environ Med. 2011 Oct;53(10):1146-54.

46. Surani S, Hesselbacher S, Guntupalli B, Surani S, Subramanian S. Sleep Quality and Vigilance Differ Among Inpatient Nurses Based on the Unit Setting and Shift Worked. J Patient Saf. 2015 Dec;11(4):215-20.

47. Ruggiero JS, Redeker NS, Fiedler N, Avi-Itzhak T, Fischetti N. Sleep and psychomotor vigilance in female shift workers. Biol Res Nurs. 2012 Jul;14(3):225-35

48. Lamond N, Dorrian J, Burgess H, Holmes A, Roach G, McCulloch $\mathrm{K}$, et al. Adaptation of performance during a week of simulated night work. Ergonomics. 2004;47(2):154-65.

49. Koopmans L, Bernaards CM, Hildebrandt VH, Schaufeli WB, De Vet Henrica CW, Van Der Beek AJ. Conceptual frameworks of individual work performance: A systematic review. J Occup Environ Med. 2011;53(8):856-66.

50. Mullins HM, Cortina JM, Drake CL, Dalal RS. Sleepiness at work: A review and framework of how the physiology of sleepiness impacts the workplace. J Appl Psychol. 2014;99(6):1096-112.

51. Gujar N, Yoo S-S, Hu P, Walker MP. Sleep deprivation amplifies reactivity of brain reward networks, biasing the appraisal of positive emotional experiences. J Neurosci. 2011 Mar;31(12):4466-74.
52. Chuah LYM, Dolcos F, Chen AK, Zheng H, Parimal S, Chee MWL. Sleep deprivation and interference by emotional distracters. Sleep. 2010 Oct;33(10):1305-13

53. Griffin MA, Neal A. Perceptions of safety at work: a framework for linking safety climate to safety performance, knowledge, and motivation. J Occup Health Psychol. 2000;5(3):347-58.

54. Rehman A. How to Determine Poor Quality Sleep [Internet]. 2020 [cited 2021 Mar 19]. Available from: https://www.sleepfoundation. org/press-release/what-good-quality-sleep

55. Harvey AG, Stinson K, Whitaker KL, Moskovitz D, Virk H. The subjective meaning of sleep quality: a comparison of individuals with and without insomnia. Sleep. 2008 Mar;31(3):383-93.

56. Singh A. How Much Sleep Do We Really Need? [Internet]. 2021 [cited 2021 Mar 19]. Available from: https://www.sleepfoundation. org/how-sleep-works/how-much-sleep-do-we-really-need

57. National Institute of Neurological Disorders and Stroke. Brain Basics: Understanding Sleep [Internet]. 2019 [cited 2021 Mar 19]. Available from: https://www.ninds.nih.gov/Disorders/Patient-CaregiverEducation/understanding-Sleep

58. Rehman A. Sleep Drive and Your Body Check [Internet]. 2021 [cited 2021 Mar 19]. Available from: https://www.sleepfoundation.org/ circadian-rhythm/sleep-drive-and-your-body-clock

59. Potter GDM, Skene DJ, Arendt J, Cade JE, Grant PJ, Hardie LJ. Circadian Rhythm and Sleep Disruption: Causes, Metabolic Consequences, and Countermeasures. Endocr Rev. 2016 Dec;37(6):584-608.

60. Akerstedt T, Folkard S. The three-process model of alertness and its extension to performance, sleep latency and sleep length. Chronobiol Int. 1997 Mar;14(2):115-23.

61. Mesulam MM. Principles of Behavioral and Cognitive Neurology. 2nd ed. New York: Oxford University Press; 2000. pp. 1-238

62. Hagewoud R, Havekes R, Novati A, Keijser JN, Van der Zee EA, Meerlo P. Sleep deprivation impairs spatial working memory and reduces hippocampal AMPA receptor phosphorylation. J Sleep Res. 2010 Jun;19(2):280-8.

63. Hsieh S, Tsai CY, Tsai LL. Error correction maintains post-error adjustments after one night of total sleep deprivation. J Sleep Res. 2009 Jun;18(2):159-66.

64. Trujillo LT, Kornguth S, Schnyer DM. An ERP examination of the different effects of sleep deprivation on exogenously cued and endogenously cued attention. Sleep. 2009 Oct;32(10):1285-97.

65. Bayard S, Abril B, Yu H, Scholz S, Carlander B, Dauvilliers Y. Decision making in narcolepsy with cataplexy. Sleep. 2011 Jan;34(1):99-104.

66. Rotundo M. The relative importance of task, citizenship, and counterproductive performance to global ratings of job performance: a policy-capturing approach. J Appl Psychol. 2002 Feb;87(1):66-80.

67. Caruso CC, Baldwin CM, Berger A, Chasens ER, Edmonson JC, Gobel BH, et al. Policy brief: Nurse fatigue, sleep, and health, and ensuring patient and public safety. Nurs Outlook. 2019;67(5):615-9.

68. Cochran KR. An Examination of Work Characteristics, Fatigue, and Recovery Among Acute Care Nurses. J Nurs Adm. 2021;51(2):89-94.

69. Kuhn G. Circadian rhythm, shift work, and emergency medicine Ann Emerg Med. 2001 Jan;37(1):88-98.

70. Burgess PA. Optimal shift duration and sequence: recommended approach for short-term emergency response activations for public health and emergency management. Am J Public Health. 2007;97 Suppl 1:88-92.

71. Knupp AM, Patterson ES, Ford JL, Zurmehly J, Patrick T. Associations Among Nurse Fatigue, Individual Nurse Factors, and Aspects of the Nursing Practice Environment. J Nurs Adm. 2018 Dec;48(12):642-8.

72. Whitehead DC, Thomas HJ, Slapper DR. A rational approach to shift work in emergency medicine. Ann Emerg Med. 1992 Oct;21(10):1250-8.

73. Webb WB, Agnew HWJ. Stage 4 sleep: influence of time course variables. Science. 1971 Dec;174(4016):1354-6.

74. Grimani A, Aboagye E, Kwak L. The effectiveness of workplace nutrition and physical activity interventions in improving productivity, work performance and workability: A Systematic Review. 2019;1-12. 


\section{APPENDIX}

Appendix A. The detailed summary of findings referring to Table 2

\begin{tabular}{|c|c|c|c|c|c|c|c|}
\hline Authors & LoE & Relevant studies & Study design & Population & $\begin{array}{l}\text { Total of } \\
\text { Subjects }\end{array}$ & Source of data & $\begin{array}{l}\text { Measure } \\
\text { of risk }\end{array}$ \\
\hline $\begin{array}{l}\text { Whelehan DF } \\
\text { et al.1.1 }\end{array}$ & $3 A$ & $\begin{array}{l}33 \text { studies } \\
\text { (17 studies have } \\
\text { good quality, } \\
16 \text { studies still } \\
\text { unclear) }\end{array}$ & $\begin{array}{l}\text { SR of } P C, R C T, C C \text {, } \\
R C, C S \text {, and } M A A\end{array}$ & $\begin{array}{l}\text { Surgeons } \\
\text { (undergraduate, } \\
\text { intern, resident, } \\
\text { and attending) }\end{array}$ & 880 & $\begin{array}{l}\text { Validated simulated } \\
\text { assessment tools to } \\
\text { measure the varying } \\
\text { level of skill proficiency } \\
\text { among surgeons }\end{array}$ & $\begin{array}{l}\text { Proportion } \\
\text { of changes in } \\
\text { performance } \\
\text { (\%) and p-value }\end{array}$ \\
\hline $\begin{array}{l}\text { Di Muzio M } \\
\text { et al. (a) } 23\end{array}$ & $3 \mathrm{~A}$ & $\begin{array}{l}8 \text { of } 19 \text { included } \\
\text { studies }\end{array}$ & $\begin{array}{l}\text { SR of CS prospective } \\
\text { study, descriptive study, } \\
\text { web-based survey, and } \\
\text { longitudinal study }\end{array}$ & Nurses & 29,297 & $\begin{array}{c}\text { Surveys; validated } \\
\text { questionnaire; shift } \\
\text { reports; BFI; and PSQI. }\end{array}$ & value \\
\hline
\end{tabular}

\begin{tabular}{|c|c|c|c|c|}
\hline $\begin{array}{l}\text { Gates M } \\
\text { et a. }{ }^{22}\end{array}$ & $3 \mathrm{~A}$ & $\begin{array}{c}47 \text { studies (for SR) } \\
6 \text { studies f(for MA); } \\
62 \% \text { study was a } \\
\text { high risk of bias }\end{array}$ & $\begin{array}{l}\text { SR-MA partially of CS } \\
\text { (72\%), before-after } \\
\text { study, PC, RC, RCT, } \\
\text { time series, and non- } \\
\text { comparative studies, }\end{array}$ & $\begin{array}{l}\text { Physicians (doctors } \quad 36,190 \\
\text { of all specialties) }\end{array}$ \\
\hline
\end{tabular}

$\begin{array}{cc}\text { MBI; Pines BM; } & \text { OR, MD, and } \\ \text { SMBM; PSQl; Stress } & \begin{array}{c}\text { p-value } \\ \text { Pals }\end{array}\end{array}$

parameters; GHQ-12;

WRSQ; Jenkins Scale,
VAS; AUDIT: OIDS: 4,5,7-point Likert Scale ESS; Laparoscopic Simulation (LapSimGyn)
HVIT: Battery: Test
Reation HVLT; Battery; Test
Reaction 5; and WAI

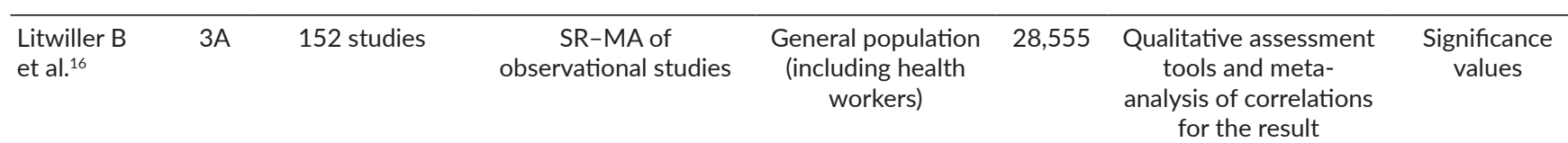

- Sleep deprivation created worse technical proficiency among surgeons (described in 16 studies), although two studies mentioned positive - Sleep deprivation caused an 11.9-32\% decrement in performance, not statistically significant-lack of evidence about the influence of experience, sleep type, and duration on technical proficiency.

The impact of sleeplessness on the night shift are:

(ave

- The 12.5-hour shifts (day and night) have OR $\sim 2$ of accidents and medication errors compared to 8.5-hour shifts, increasing patients' deaths

- About $56 \%$ of night-shift nurses report sleep deprivation; $75 \%$ of those have $<4.7$ hours of sleep and emerges more prone to treatment errors - Impaired communication skills (mentioned in one study): Nurses who work 12-hour shifts (day and night) often have more difficulty

- communicating with patients and poor teamwork quality.
Disturbed sleep and resulting fatigue (stated in two studies): Night shift nurses got more significant tiredness and worse sleep quality than -

- Impaired cognition (showed in one study): Lack of sleep resulted in fatigue and cognitive dysfunction, potentially affecting patient and

Impact of fatigue, insufficient sleep, and overnight-related work to:

- Aspect of health and well-being (described in 28 studies), sleep deprivation:

- Increased burnout (OR $0.84 ; 95 \% \mathrm{Cl}: 0.75-0.94 ; \mathrm{p}=0.002$ ), and more prevalent among the sleep-deprived compared to normal sleep $(47.6 \%$ vs $16.3 \%$, p $<0.001)$. Burnt-out physicians de - Was associated with work-related stress based on GHQ-12 $p<0.0001$, WRSQ $p<0.001$, VAS $p<0.05$, and increased biochemical, physiological

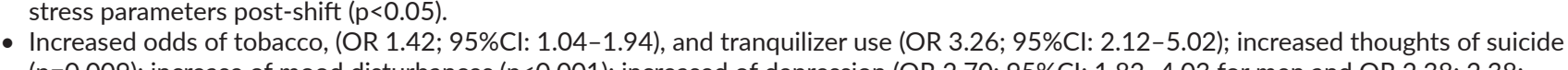

$95 \%$ Cl $1111-5,10$ for women) than to day shift.

- Predicted the intention to retire early or not satisfied in the job (OR 2.91; $95 \%$ Cl: 1.11-7.6, $\mathrm{p}<0.05)$; became a predictor of reduced life satisfaction (OR $0.44 ; 95 \%$ Cl: $0.20-0.67$, $p<0.05$ ); sleep deprivation was correlated to the lower marital satisfaction ( $p<0.001$ ); and reduced Sleep deprivation increased odds of sickness presenteeism (OR 292.95\% Cl: 119-7.16, p<005).

- Aspect of performance and risk of errors (explained in 21 studies), sleep deprivation:

In MA of six studies: showed no difference in operating time (refer to efficiency) between sleep-deprived and non-sleep-deprived surgeons

- Did not influence laparoscopic simulation skill; but disrupted performance on a virtual ring transfer task ( $p<0.05)$, made longer reaction times (690.8 $\pm 73.4 \mathrm{vs} .746 .5 \pm 113.7 \mathrm{~ms}$ ), and reduced concentration ability (26.4 $23.5 \mathrm{vs.} 56.3 \pm 23.0, p=0.007$ ) among surgeon, following by reduced HVLT

lity among physicians ( $p<0.001)$, and fatigue was a predictor for perceived quality of care $(p<0.05)$.

high association betweal errors among surgeons, anesthesiologists a ar

- Aspect of patient outcomes and safety (Included in six cohorts), sleep deprivation:

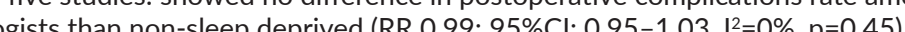

- In MA, four studies showed that patient mortality is not correlated with sleep deprivation among surgeons and obstetrician-gynecologists (RR $\left.0.98 ; 95 \% \mathrm{Cl} 0.84-1.15,{ }^{2}=0 \%, \mathrm{p}=0.87\right)$

Sleep quality and quantity were correlated.

.

State negative affect
Turnover cognition

Job satisfaction

- Task performance

Contextual performance
Safety performance 
Appendix A. The detailed summary of findings referring to Table 2 (continued)

\begin{tabular}{|c|c|c|c|c|c|c|c|c|}
\hline Authors & LoE & Relevant studies & Study design & Population & $\begin{array}{c}\text { Total of } \\
\text { Subjects }\end{array}$ & Source of data & $\begin{array}{l}\text { Measure } \\
\text { of risk }\end{array}$ & Outcomes of Studies: Effect of Sleep Deprivation towards Work Performance \\
\hline \multirow[t]{5}{*}{$\begin{array}{l}\text { Kucharczyk } \\
\text { ER et al.1.5 }\end{array}$} & $3 \mathrm{~A}$ & $\begin{array}{l}2 \text { of } 6 \text { included } \\
\text { studies }\end{array}$ & SR of $1 \mathrm{CC}$ and $1 \mathrm{CS}$ & $\begin{array}{l}\text { General worker } \\
\text { and healthcare } \\
\text { professional }\end{array}$ & 7,968 & Survey & $\begin{array}{l}\text { The odds of an } \\
\text { impact (p-value) }\end{array}$ & Sleep quality disturbances significantly lowered job satisfaction (all studies have $p<0.01$ ). \\
\hline & & $\begin{array}{l}5 \text { of } 11 \text { included } \\
\text { studies }\end{array}$ & $\mathrm{SR}$ of $2 \mathrm{CC}$ and $3 \mathrm{CS}$ & $\begin{array}{l}\text { General worker } \\
\text { and healthcare } \\
\text { professional }\end{array}$ & 36,229 & $\begin{array}{l}\text { Survey (postal or } \\
\text { internet-based) } \\
\text { and interview }\end{array}$ & $\begin{array}{l}\text { The odds of an } \\
\text { impact (p-value) }\end{array}$ & Sleep quality disruption significantly decreased workplace productivity (all studies have $p<0.01$ ). \\
\hline & & $\begin{array}{c}6 \text { of } 16 \text { included } \\
\text { studies }\end{array}$ & $\begin{array}{l}\text { SR of } 2 \text { historical cohort } \\
\text { studies and } 1 \text { CC }\end{array}$ & $\begin{array}{l}\text { General worker } \\
\text { and physician }\end{array}$ & 48,907 & Survey & $\begin{array}{l}\text { The odds of an } \\
\text { impact (p-value) }\end{array}$ & $\begin{array}{l}\text { Sleep quality deprivation significantly increased work disability (two studies have } \mathrm{p}<0.001 \text { ) and desire to change career and more likely will } \\
\text { slow career progression (one study has } \mathrm{p}<0.01 \text { ). }\end{array}$ \\
\hline & & $\begin{array}{l}6 \text { of } 16 \text { included } \\
\text { studies }\end{array}$ & $\begin{array}{l}\text { SR of } 4 \text { CS, } \\
1 \text { longitudinal study, } \\
\text { and 1 cohort study }\end{array}$ & $\begin{array}{l}\text { General worker } \\
\text { and healthcare } \\
\text { professional }\end{array}$ & 37,936 & $\begin{array}{l}\text { Survey (postal or } \\
\text { internet-based) } \\
\text { and interview }\end{array}$ & $\begin{array}{l}\text { The odds of an } \\
\text { impact (p-value) }\end{array}$ & Having trouble sleeping significantly enhanced absenteeism's odds (three studies have $p<0.05$, and the other three have $p<0.01$ ). \\
\hline & & $\begin{array}{l}5 \text { of } 11 \text { included } \\
\text { studies }\end{array}$ & $\begin{array}{l}\text { SR of } 3 \mathrm{CS}, \\
\text { longitudinal study, and } \\
1 \text { prospective study }\end{array}$ & $\begin{array}{l}\text { General worker } \\
\text { and healthcare } \\
\text { professional }\end{array}$ & 170,155 & $\begin{array}{l}\text { Survey (postal or } \\
\text { internet-based) } \\
\text { and interview }\end{array}$ & $\begin{array}{l}\text { The odds of an } \\
\text { impact (p-value) }\end{array}$ & Disturbed sleep quality and insomnia significantly elevated the odds of work accidents (all studies have $p<0.05$ ). \\
\hline $\begin{array}{l}\text { Wagstaff AS } \\
\text { et al.14 }\end{array}$ & $3 \mathrm{~A}$ & $\begin{array}{l}3 \text { of } 14 \text { included } \\
\text { studies }\end{array}$ & $\begin{array}{l}\text { SR-MA partially of CC, } \\
\text { CS, RS, CT, } \mathrm{FT}, \mathrm{PC}, \mathrm{RC}\end{array}$ & $\begin{array}{c}\text { Female nurse, blood } \\
\text { donor workers, } \\
\text { other health- } \\
\text { related workers }\end{array}$ & 26,552 & $\begin{array}{c}\text { Self-reported by } \\
\text { questionnaires } \\
\text { and national } \\
\text { Ingitudinal survey }\end{array}$ & $\mathrm{IHR}, \mathrm{OR}$, and RR & $\begin{array}{l}\text { Sleep-deprived healthcare professional was more likely to developing work work-related injuries with OR 1.88; 95\% Cl: 0.88-4.02, RR 1.38; } \\
95 \% \text { Cl: } 0.93-2.00 \text {, and IHR 1.30; } 95 \% \text { Cl: 1.12-1.52) }\end{array}$ \\
\hline $\begin{array}{l}\text { Di Muzio M } \\
\text { et al. (b) }{ }^{26}\end{array}$ & $2 \mathrm{C}$ & N/A & Cross-sectional study & Nurses & 86 & $\begin{array}{l}\text { Interview; PSQl; TSS to } \\
\text { assess tiredness; } \\
\text { PVT to assess attention; } \\
\text { KSS to assess level } \\
\text { of sleepiness }\end{array}$ & $\begin{array}{l}\text { The significance } \\
\text { of an impact } \\
\text { (p-value) }\end{array}$ & $\begin{array}{l}\text { - Tiredness was more significant after the night shift than the morning and afternoon shifts }(p<0.001) \text {. } \\
\text { Sleepiness was higher in the night shift than morning and affernoon shitts ( } p<0.001) \text {. } \\
\text { Response times were higher in the night shift than the morning and affernoon shifts }(p<0.001) \text {. } \\
\text { Lapses in the night shift were greater than the afternoon shift }(p<0.05) \text {, but differences in the lapses between night shift vs. morning shift } \\
\text { were not significant }(p=0.46) \text {. }\end{array}$ \\
\hline Cho SS et al. ${ }^{25}$ & $2 \mathrm{C}$ & N/A & Cross-sectional study & General workers & 4,146 & $\begin{array}{l}\text { Web-based } \\
\text { Questionnaire }\end{array}$ & HRPL & Fixed night work significantly reduced $7.7 \%$ of productivity (95\% Cl: $1.8-13.7)$. \\
\hline $\begin{array}{l}\text { Costac } \\
\text { et al. } 29\end{array}$ & $2 \mathrm{C}$ & N/A & Cross-sectional study & $\begin{array}{l}\text { Residents (medical, } \\
\text { surgical, services, } \\
\text { and anesthesia) }\end{array}$ & 80 & $\begin{array}{l}\text { ESS; PSQI; MMSE; } \\
\text { and POMS }\end{array}$ & $\begin{array}{l}\text { The significance } \\
\text { of an impact } \\
\text { (p-value) }\end{array}$ & $\begin{array}{l}\text { - Within the sleep-deprived subjects, no daytime sleepiness, sleep disorders, intellectual efficiency changes, and cognitive impairment } \\
\text { were found } \\
\text { - Mood states analysis resulted in a borderline level of anger-hostility values and fatigue inertia (T-Score 50) in medical and services area } \\
\text { r residents (p<0.0001) } \\
\text { Vigour-activity was increased in all residents. }\end{array}$ \\
\hline $\begin{array}{l}\text { Behrens T } \\
\text { et al. } .00\end{array}$ & $2 \mathrm{C}$ & N/A & Cross-sectional study & $\begin{array}{l}\text { Female health } \\
\text { workers (67 } \\
\text { nurses, } 7 \text { medical } \\
\text { lab assistants) }\end{array}$ & 74 & $\begin{array}{l}\text { Interview and three } \\
\text { minute PVT (PVT-B) }\end{array}$ & $\begin{array}{l}\text { Beta distribution } \\
\text { (Beta-logistic } \\
\text { models) }\end{array}$ & $\begin{array}{l}\text { - Reaction times were increased at the end of the night shift ( } \beta=7.64 ; 95 \% \mathrm{Cl}: 0.94-14.35) \\
\text { The number of lapses was higher in the night shift compared to the day shift (exp( }(\beta)=1.55 ; 95 \% \mathrm{Cl} 1.16-2.08) \\
\text { - A combined index of response speed and accuracy was reduced after night shifts }(\beta=-15.52 ; 95 \% \mathrm{Cl}-27.49-(-3.46))\end{array}$ \\
\hline $\begin{array}{l}\text { Ganesan S } \\
\text { et al.27 }\end{array}$ & $2 \mathrm{C}$ & N/A & Cross-sectional study & $\begin{array}{l}11 \text { Doctors } \\
\text { and } 39 \text { Nurses }\end{array}$ & 52 & $\begin{array}{l}\text { Questionnaire; } \\
\text { actigraphs; sleep diaries; } \\
\text { KSS; JDS; PVT; and } \\
\text { self-report questions } \\
\text { assessing the level of } \\
\text { concentration task } \\
\text { difficulty and motivation }\end{array}$ & $\mathrm{p}$-value & 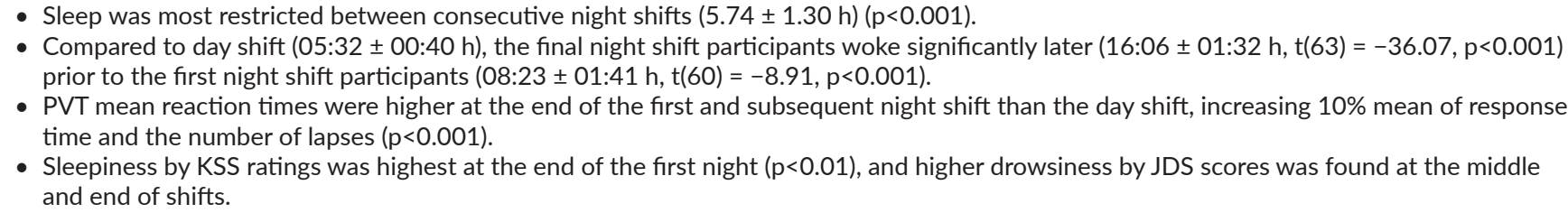 \\
\hline
\end{tabular}

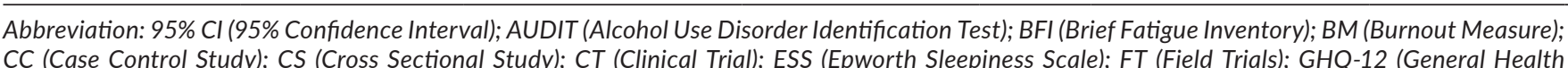
CC (Case Control Study); CS (Cross Sectional Study); CT (Clinical Trial); ESS (Epworth Sleepiness Scale); FT (Field Trials); GHQ-12 (General Health Scale); KSS (Karolinska Sleepiness Scale); LOE (Level of Evidence); MA (Meta-Analysis), MBI (Maslach Burnout Inventory); MD (Mean Differencese), MMSE (Mini Mental State examination); N/A (Not Applicable); OR (Odd ratios); PC (Prospective Cohort Study); POMS (Profile of Mood States);

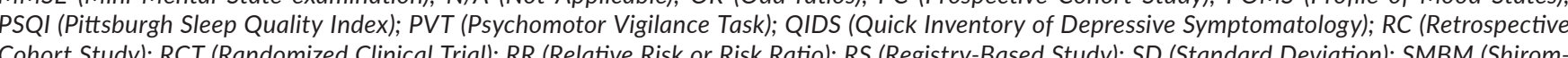
Cohort Study); RCT (Randomized Clinical Trial); RR (Relative Risk or Risk Ratio); RS (Registry-Based Study); SD (Standard Deviation); SMBM (Shirom-
Melamed Burnout Meesure); $R$ (Systematic Review); TSS (Tiredness Symptoms Scale); VAS (Visual Analog Scale); WAI (Work Ability Index); and
WRSQ (Work-Related Stress Questionnaire). 